\title{
Two Rare Cases of Tinea Corporis Caused by Trichophyton verrucosum and Trichophyton interdigitale in a Teenage Girl
}

\author{
Caroline B. Crain ${ }^{1}$, Arathi Rana ${ }^{1}$, Frank T. Winsett ${ }^{1}$, Michael G. Wilkerson ${ }^{1}$ \\ 1. Dermatology, University of Texas Medical Branch, Galveston, USA \\ $\square$ Corresponding author: Caroline B. Crain, cbcrain@utmb.edu \\ Disclosures can be found in Additional Information at the end of the article
}

\section{Abstract}

We present two cases of tinea corporis caused by Trichophyton verrucosum and Trichophyton interdigitale in a teenage girl who works with farm animals. We describe the differences in presentation between zoophilic dermatophytes and anthropophilic dermatophytes. Also, we report some of the typical features of the two rare species, T. verrucosum and T. interdigitale. This case is significant to dermatology as it raises awareness about these uncommon zoophilic dermatophytoses and demonstrates the importance of educating patients about their mode of infection.

Categories: Dermatology, Miscellaneous, Infectious Disease

Keywords: tinea corporis, trichophyton verrucosum, trichophyton interdigitale, zoophilic dermatophytes, majocchi's granuloma

\section{Introduction}

Dermatophytoses, also known as tinea or ringworm, are contagious mycoses of the skin that can cause infection in a wide range of mammals including pet animals and livestock. The three most common zoonotic dermatophytes are Microsporum canis primarily from cats and dogs, Trichophyton mentagrophytes primarily from rodents, and Trichophyton verrucosum primarily from cattle and other ruminants [1]. Herein, we present two cases of tinea corporis caused by Trichophyton verrucosum and Trichophyton interdigitale in a teenage girl who works with farm animals.

Received 07/31/2019

Review began 08/02/2019 Review ended 08/03/2019 Published 08/05/2019

(c) Copyright 2019

Crain et al. This is an open access article distributed under the terms of the Creative Commons Attribution License CC-BY 3.0., which permits unrestricted use, distribution, and reproduction in any medium, provided the original author and source are credited.

\section{Case Presentation}

A 17-year-old female presented to the dermatology clinic with a pruritic rash on her left arm that had been present for two months. The patient was an aspiring veterinarian and worked with goats, lambs, and sheep in her spare time. Physical examination revealed annular erythematous indurated plaques with several pustules and excoriations on her left shoulder, arm, and hand (Figures 1,2).

How to cite this article

Crain C B, Rana A, Winsett F T, et al. (August 05, 2019) Two Rare Cases of Tinea Corporis Caused by Trichophyton verrucosum and Trichophyton interdigitale in a Teenage Girl. Cureus 11(8): e5325. DOI 10.7759 /cureus. 5325 


\section{Cureus}

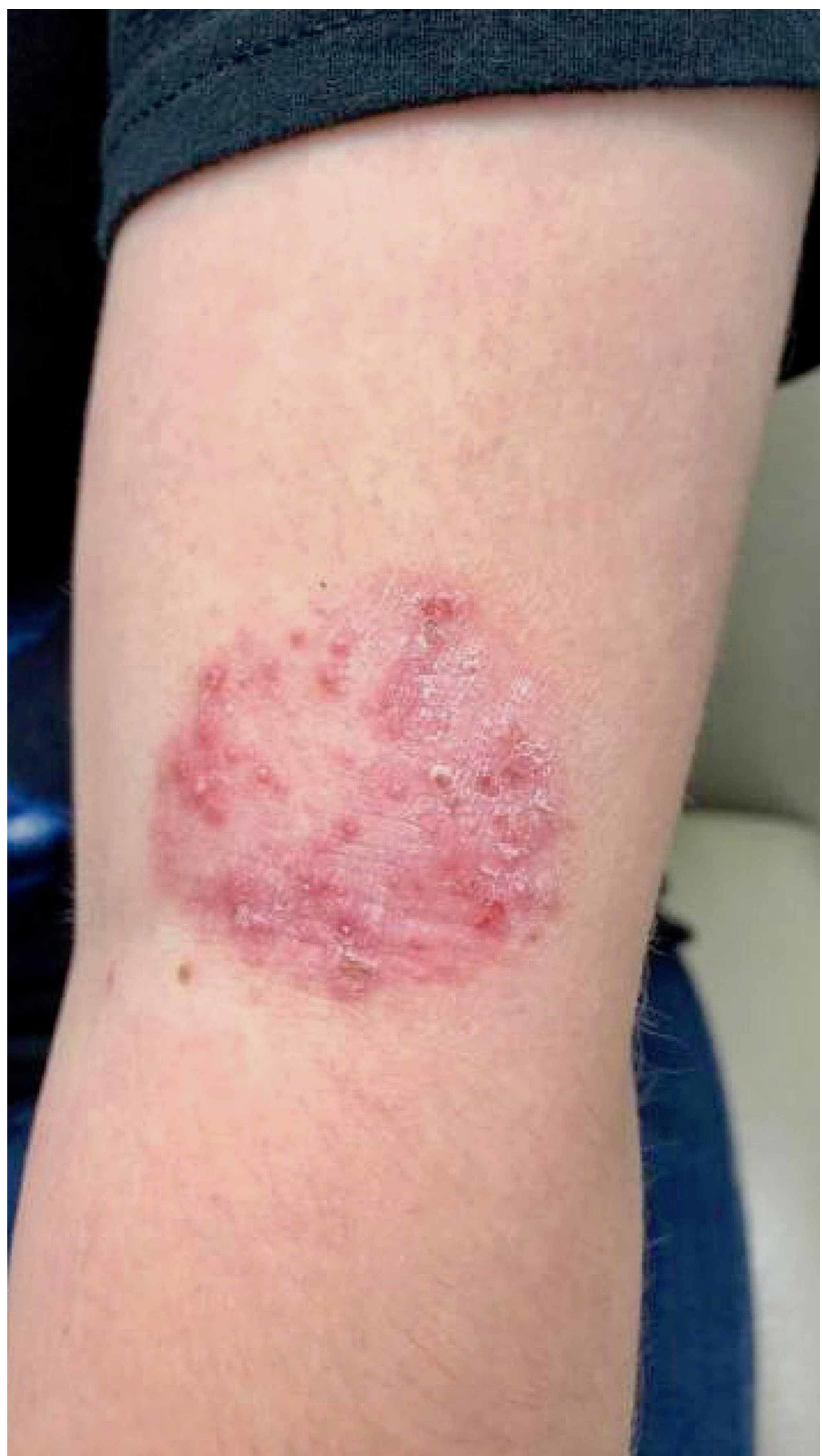

FIGURE 1: Patient's initial presentation revealing annular, 
Cureus

erythematous, indurated plaque with pustules and excoriations present on the patient's left arm consistent with tinea corporis due to $T$. verrucosum. 


\section{Cureus}

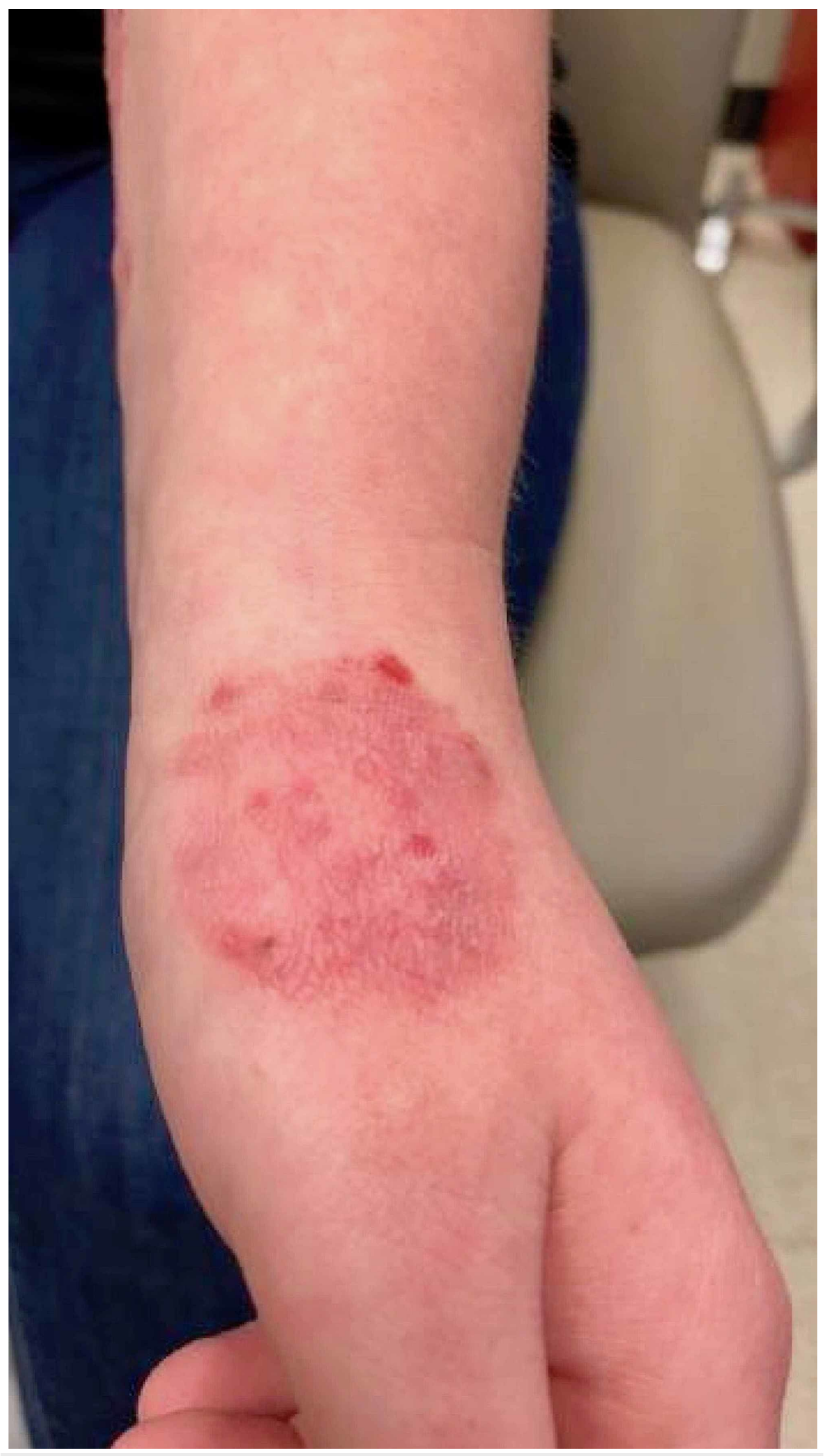

FIGURE 2: Patient's initial presentation revealing annular, 


\section{erythematous, indurated plaque present on the patient's left hand consistent with tinea corporis due to T. verrucosum.}

The patient had a negative potassium hydroxide $(\mathrm{KOH})$ preparation in clinic, but fungal culture and internal transcribed spacer (ITS) sequencing were consistent with Trichophyton verrucosum. A punch biopsy revealed prominent acute and chronic perifollicular inflammation consistent with a diagnosis of Majocchi's granuloma. After one month of treatment with terbinafine 250 mg, the lesions resolved.

About a year later, the patient presented again with a rash on her arms and left leg that had been present for several weeks. She reported continued exposure to farm animals. Physical examination revealed scattered erythematous papules on her bilateral arms, left leg, and chest. Tinea corporis was suspected, but a $\mathrm{KOH}$ preparation was negative in clinic. However, a fungal culture confirmed the diagnosis and was positive for Trichophyton interdigitale. It was successfully treated with another course of terbinafine.

\section{Discussion}

Tinea corporis usually presents as a pruritic, erythematous, scaling papule or plaque that spreads centrifugally resulting in an annular lesion [1]. Zoophilic dermatophytes tend to cause significant inflammation and can lead to the development of crusts, vesicles, papules, or pustules [2]. Majocchi's granuloma develops when fungal organisms invade the dermis creating granulomatous inflammation around the hair follicle [3]. Typically, fungal hyphae and spores can be detected within and around the follicle [3].

T. verrucosum, a zoophilic dermatophyte species, is the most common cause of ringworm in cattle and other ruminants [1]. It is more prevalent in younger animals and is transmitted by direct contact with affected animals or through contaminated fomites [4]. T. interdigitale is one of four species grouped under the T. mentagrophytes complex and includes anthropophilic and zoophilic strains [5]. The zoophilic strains typically cause more severe inflammatory lesions than the anthropophilic strains, and patients usually have a history of animal contact [6]. Although it may not alter the treatment plan, strain differentiation is important for determining the infection source and for epidemiological surveillance. ITS sequencing of ribosomal deoxyribonucleic acid (DNA) is considered the gold standard for molecular identification of dermatophytes [7].

\section{Conclusions}

In conclusion, this case raises awareness about the two zoophilic dermatophytes, T. verrucosum and T. interdigitale and demonstrates the importance of educating patients about their mode of infection. ITS sequencing should be considered in patients with exposure to farm animals who are diagnosed with tinea corporis.

\section{Additional Information}

\section{Disclosures}

Human subjects: Consent was obtained by all participants in this study. Conflicts of interest: In compliance with the ICMJE uniform disclosure form, all authors declare the following:

Payment/services info: All authors have declared that no financial support was received from any organization for the submitted work. Financial relationships: All authors have declared that they have no financial relationships at present or within the previous three years with any 
organizations that might have an interest in the submitted work. Other relationships: All authors have declared that there are no other relationships or activities that could appear to have influenced the submitted work.

\section{References}

1. Chermette R, Ferreiro L, Guillot J: Dermatophytoses in animals. Mycopathologia. 2008, 166:385-405. 10.1007/s11046-008-9102-7

2. Degreef H: Clinical forms of dermatophytosis (ringworm infection). Mycopathologia. 2008, 166:257-265. 10.1007/s11046-008-9101-8

3. Boral H, Durdu M, Ilkit M: Majocchi's granuloma: current perspectives. Infect Drug Resist. 2018, 11:751-760. 10.2147/IDR.S145027

4. Roberson JR, Baird AN, Pugh DG: Diseases of the integumentary system. Sheep and Goat Medicine (Second Edition). Pugh DG, Baird AN (ed): Saunders, an imprint of Elsevier Inc, Maryland Heights, Missouri; 2012. 256-290. 10.1016/B978-1-4377-2353-3.10010-1

5. Su HA, Sun PL, Sung WW, Cheng SY, Chang HC, Yang JH, Hsiao YP: Deep dermatophytosis caused by zoophilic strain of Trichophyton interdigitale with successful treatment of itraconazole. Mycopathologia. 2017, 182:715-720. 10.1007/s11046-017-0120-1

6. Sun PL, Hsieh HM, Ju YM, Jee SH: Molecular characterization of dermatophytes of the Trichophyton mentagrophytes complex found in Taiwan with emphasis on their correlation with clinical observations. Br J Dermatol. 2010, 163:1312-1318. 10.1111/j.13652133.2010.09953.x

7. Ziolkowska G, Nowakiewicz A, Gnat S, Troscianczyk A, Zieba P, Dziedzic BM: Molecular identification and classification of Trichophyton mentagrophytes complex strains isolated from humans and selected animal species. Mycoses. 2015, 58:119-126. 10.1111/myc.12284 